\title{
A study of the effects of crude extract of purslane (rigla) on some aspects of lipid and carbohydrate metabolism in normal and diabetic male albino rats
}

\author{
Salma E. Nassar, Rezk M.El-Kholy and Romysa A. El-Sherbeny \\ Department of Physiology, Tanta University
}

\begin{abstract}
This work was performed to study the effect of crude purslane extract on some aspects of lipid and carbohydrate metabolism in normal and streptozotocin induced diabetic male albino rats. Twenty four male albino rats, were categorized into four equal groups. Group (1): normal control rats, group (2): purslane treated rats in which the rats were administrated by purslane extract in a dose of $5 \mathrm{gm} / \mathrm{kg}$ orally for three weeks, group (3):diabetic control rats and group(4): diabetic rats treated by purslane, in which the rats were administrated by purslane extract for three weeks. At the end of the experiment, the rats were scarified and blood samples were collected. The results showed significant reduction in blood levels of triglyceride, total cholesterol, $L D L$-cholesterol with significant increase in blood level of $H D L-c h o l e s t e r o l, ~ P<0.05$, and non significant change in glucose or insulin level in purslane treated group compared with normal control group. There were significant reduction in blood level of triglyceride, total cholesterol, LDL-cholesterol with significant increase in blood level of HDL-cholesterol, and non significant change in insulin level compared with the significant reduction in blood glucose level in purslane treated diabetic group compared with diabetic control group. It is concluded that crude purslane extract has beneficial effects on lipid and carbohydrates parameters both in normal and diabetic condition.
\end{abstract}

\section{INTRODUCTION}

Fresh purslane (Portulaeca oleracea) has been used for thousands of years throughout the world as medicinal herb ${ }^{(1)}$. Purslane belongs to portulacaceae purslane family, genus portulaca and olearacea species ${ }^{(2)}$. It is known as parsley or purslane in united state and Rigla in Egypt ${ }^{(3)}$

Analysis of purslane indicated that it contain many macronutrient and micronutrients ${ }^{(4)}$ as lipid, protein, carbohydrates, Omega 3 and Omega 6 , fibers and pectin as macronutrients.
Also glutathione, Alphatocopherol, $\beta$ carotene, vitamin $\mathrm{C}$, selenium, Cupper, Zinc and potassium ${ }^{(5)}$. In addition purslane is considered to be a good source of coenzyme $10\left(\mathrm{Q}_{10}\right)$ and melatonin ${ }^{(6)}$. Purslane has many medicinal uses in the ancient times, it is used as bronchodilators ${ }^{(7)}$ antiulcerogenic $^{(8)} \quad$ diuretic $^{(9)}$, in treatment of colitis and as a choleretic $^{(10)}$. Also it was used as antidiabetic $^{(\mathbf{1 1})}$. The primary antioxidant vitamins $\mathrm{A}, \mathrm{E}$ and $\mathrm{C}$ have the power to bring free radicals under control and have the power to act as 
catalyst and help to get ride of continuously formed free radicals ${ }^{(12)}$. Alphatocopherol is a chain breaking antioxidant that prevent the propagation of free radicals ${ }^{(\mathbf{1 3})}$. Beta carotene is converted to vitamin A, which acts as a powerful antioxidant that decrease low density lipoprotein oxidation $^{(\mathbf{1 4}) \text {. }}$ Vitamin $\mathrm{C}$ is antioxidant vitamin that protects low density lipoprotein cholesterol from oxidative damage $^{(\mathbf{1 5})}$. The antioxidant minerals of purslane are essential in protection of the body from continues formation of free radicals that cause tissue damage. Selenium is one of the most important mineral acting as antioxidative enzyme modulator for the formation of selenium dependant glutathione peroxidase ${ }^{(16)}$. Also zinc, manganese and copper form part of the production of superoxide dismutase enzyme ${ }^{(17)}$

The aim of the present work was to study the effect of crude alcoholic extract of purslane on some aspects of lipid and carbohydrate metabolism in normal and streqtozotocin- induced diabetic male albino rats.

\section{MATERIAL \& METHODS}

\section{Preparation of crude plant materials:}

5 kilograms of the fresh leaves of purslane (Rigla) were spread on paper sheets and dried under shade at room temperature for 14 days, then crushed and stored.

\section{Preparation of the $10 \%$ ethanol} extract:

The whole amount of dried plant was mixed with aqueous ethanol $(90 \%$ $\mathrm{H}_{2} \mathrm{O}+10 \%$ ethanol) for four hours and filtered, then ethanol was removed by evaporation $^{(\mathbf{1 8 )}}$. The extract was weighted and suspended in water where each 100 gram were suspended in $100 \mathrm{~mL}$ water so each $1 \mathrm{~mL}$ contain 1 gram purslane extract and administrated orally in a doe of 5 $\mathrm{gm} / \mathrm{kg}$ body weight daily ${ }^{(4)}$, by intragastric tube.

\section{The animals:}

This study was conducted on 24 male albino rats weighting 200-250 gm. The rats were housed in an isolated animal cages in a standard animal laboratory room and had free access to water and food.

\section{Experimental protocol:}

The rats 24 were randomly divided into four equal groups each containing 6 rats:

1) Normal control group: The rats had free access for water and food for three weeks.

2) Purslane group: The rats received crude purslane extract in a dose of 5 $\mathrm{gm} / \mathrm{kg}$ body weight orally for three weeks.

3) Diabetic control group: Diabetes was induced by a single intraperitoneal injection of streptozotocin $50 \mathrm{mg} / \mathrm{kg}^{(19)}$, and the rats received water for three weeks.

4) Purslane treated diabetic group: The streptozotocin induced diabetic rats received crude purslane extract orally in a dose of $5 \mathrm{gm} / \mathrm{kg}$ daily for three weeks.

At the end of experimental period, the rats were anaesthetized by intraperitoneal injection of pentobarbital sodium in a dose of 50 $\mathrm{mg} / \mathrm{kg}$ body weight ${ }^{(\mathbf{2 0})}$. The rats were scarified and blood samples were collected and serum was separated for determination of: 
1. Determination of triglycerides by the method described by Fossati and Principe $^{(21)}$.

2. Determination of total cholesterol according to the method of Ratliff and Hall ${ }^{(22)}$.

3. Determination of high density lipoprotein cholesterol by the method of Richmond ${ }^{(23)}$

4. Determination of low density lipoprotein cholesterol by the method of Fruchart ${ }^{(24)}$.

5. Determination of serum insulin level according to the method of Burrin ${ }^{(25)}$

6. Determination of blood glucose level according to the method of Tietz $^{(26)}$

\section{Statistical analysis:}

Results were tabulated, and analysis was performed with statistical package for social science (SPSS version 13). Comparison between the studied groups was performed with independent samples student t-test for comparison means. F value of analysis of variance (ANOVA) was calculated. $P$ valve of $<0.05$ were considered statistically significant

\section{RESULTS}

The results of the present work showed that, the crude purslane extract was administrated orally in a dose of $5 \mathrm{gm} / \mathrm{kg}$ body weight daily for three weeks to normal and streptozotocin induced diabetic male albino rats showed significant reduction of blood triglycerides and low density lipoprotein and significant increase in high density lipoprotein, $(\mathrm{P}<0.05)$ in relation to normal control rats. Also there were significant reduction of high density lipoprotein and insulin and significant increased in blood triglycerides, cholesterol, low density lipoprotein and blood glucose levels $(\mathrm{P}<0.05)$ in streptozotocin induced diabetic rats in relation to normal controls rats. Administration of crude purslane extract to streptozotocin induced diabetic rats showed significant reduction in blood level of triglyceride, cholesterol, low density lipoprotein, glucose in relation to diabetic control group $(\mathrm{P}<0.05)$. Also there was significant increased in blood levels of high density lipoprotein $(\mathrm{P}<0.05)$ and non significant increase of blood insulin, table (1).and figures (1-6). 
Table (1): Effect of oral administration of crude purslane extract on the serum levels of some lipid parameters, glucose and insulin in normal and streptozotocin induced diabetic albino rats

\begin{tabular}{|c|c|c|c|c|}
\hline $\begin{array}{c}\text { Group } \\
\text { (Mean of } 6+\mathrm{SD})\end{array}$ & Control & Purslane & $\begin{array}{l}\text { Diabetic } \\
\text { control }\end{array}$ & $\begin{array}{c}\text { Diabetes with } \\
\text { Purslane }\end{array}$ \\
\hline Triglycerides mg/dl & $143.36+6.43$ & $135.28+3.63 *$ & $200.6+5.95$ & $172.1 \pm 7.3 *$ \\
\hline Cholesterol mg/dl & $110.05 \pm 7.91$ & $108.91+8.24$ & $238.1 \pm 10.34$ & $190.6 \pm 9.24 *$ \\
\hline High density lipoprotein $\mathrm{mg} / \mathrm{dl}$ & $65.1 \pm 3.16$ & $73+2.76^{*}$ & $30.95+2.45$ & $34.82+2.89 *$ \\
\hline Low density lipoprotein $\mathrm{mg} / \mathrm{dl}$ & $48.24+3.6$ & $39.43+2.45^{*}$ & $87.4 \pm 5.14$ & $69.6 \pm 3.57 *$ \\
\hline Glucose $\mathrm{mg} / \mathrm{dl}$ & $93.84+1.78$ & $92.77+3.68$ & $206.8+4.34$ & $174.7 \pm 8.52 *$ \\
\hline Insulin IU/dl & $11.02+1.09$ & $11.14+1.49$ & $7.05 \pm 0.75$ & $7.34+0.74 *$ \\
\hline
\end{tabular}

$*=$ denotes statistical significance

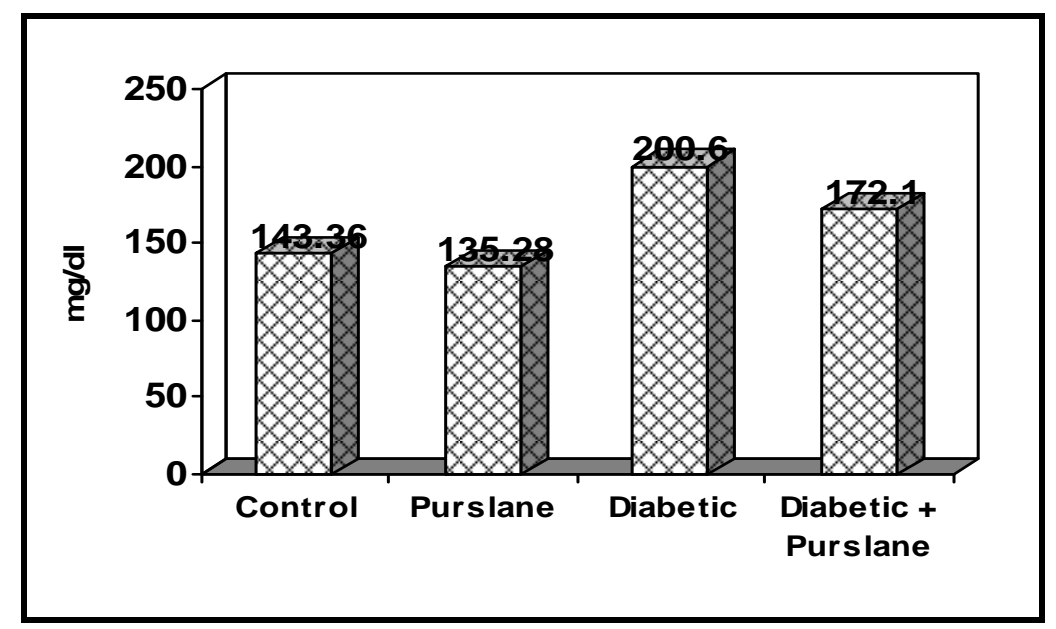

Fig. (1): Effect of oral crude purslane extract administration on triglyceride normal and streptozotocin induced diabetic level $(\mathrm{mg} / \mathrm{dl})$ in male albino rats. 


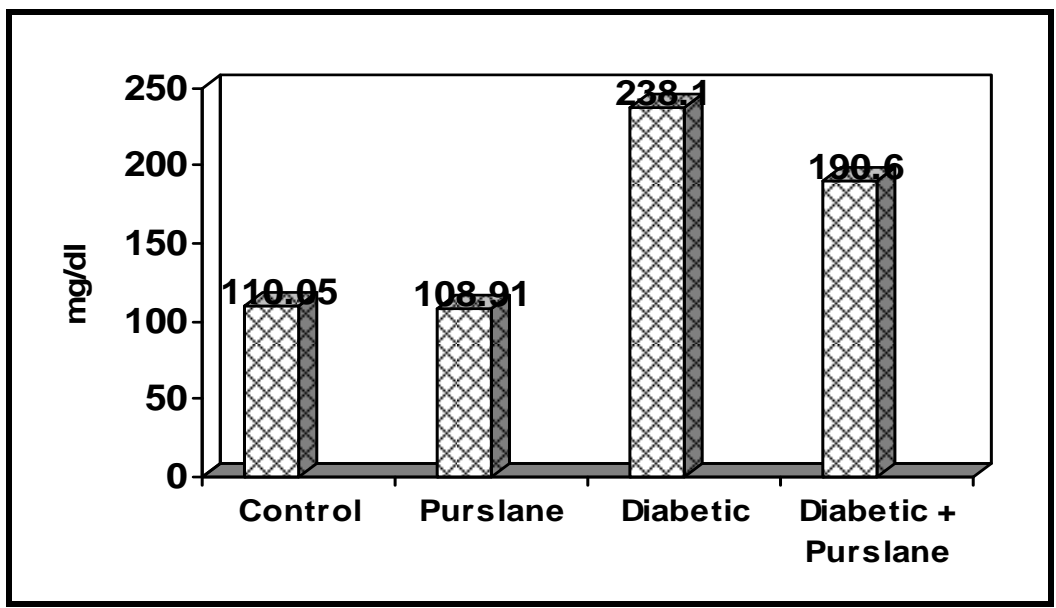

Fig. (2): Effect of oral crude purslane extract administration on cholesterol level $(\mathrm{mg} / \mathrm{dl})$ in normal and streptozotocin induced diabetic male albino rats

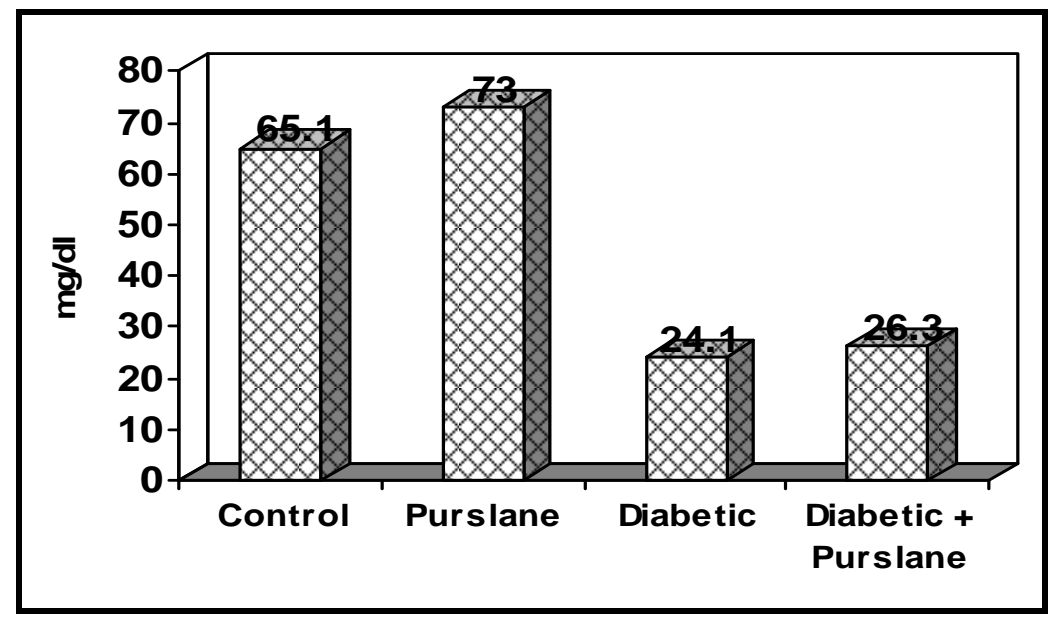

Fig. (3): Effect of oral crude purslane extract administration on high density lipoprotein level $(\mathrm{mg} / \mathrm{dl})$ in normal and streptozotocin induced diabetic male albino rats. 


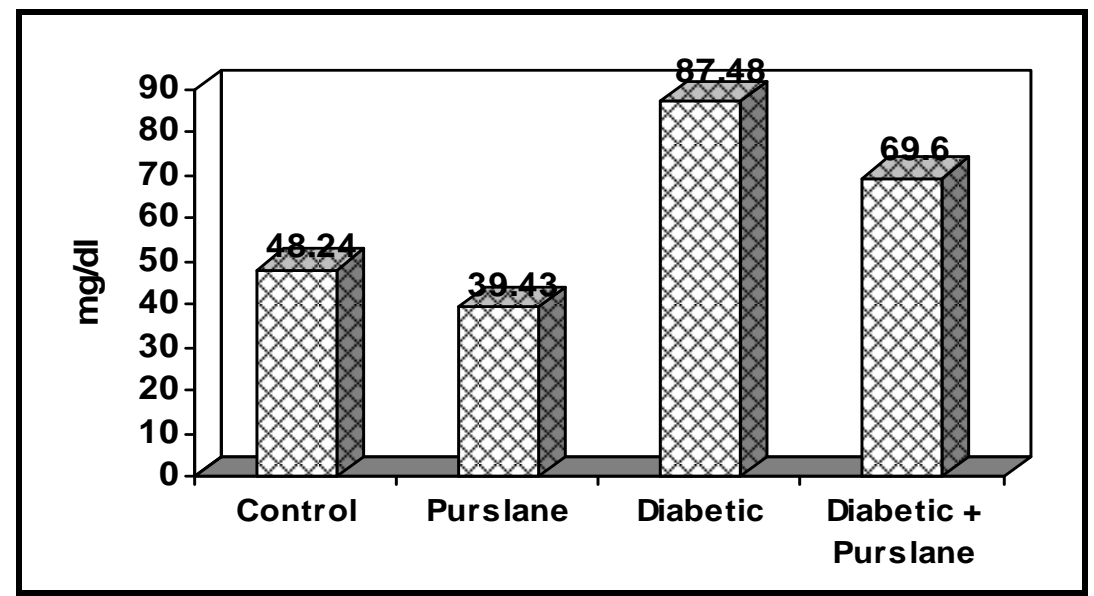

Fig. (4): Effect of oral crude purslane extract administration on low density lipoprotein level in normal and streptozotocin induced diabetic male albino rats

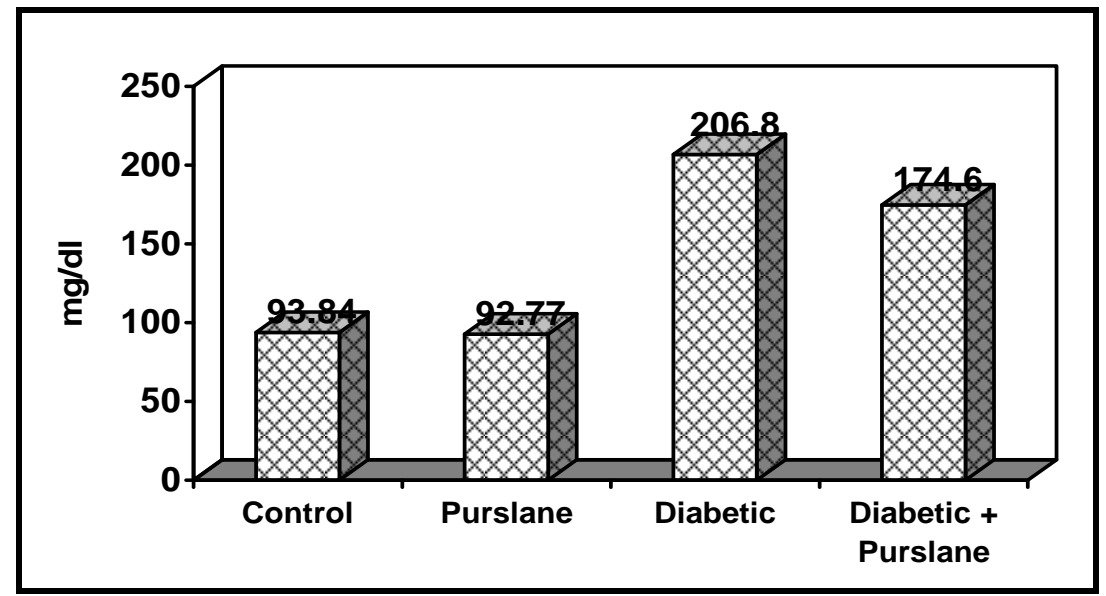

Fig. (5): Effect of oral crude purslane extract administration on blood glucose level $(\mathrm{mg} / \mathrm{dl})$ in normal and streptozotocin induced diabetic male albino rats 


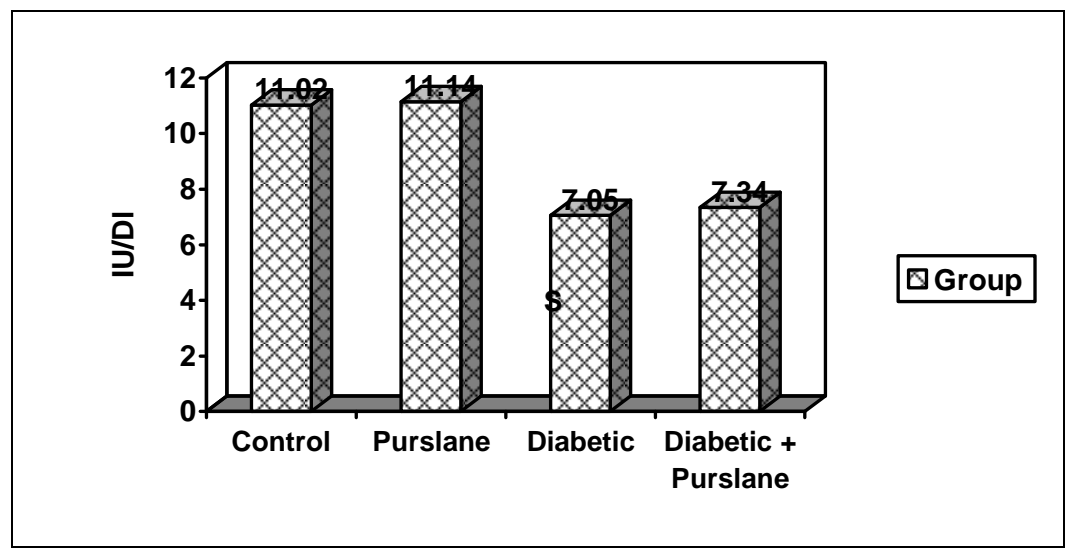

Fig. (6): Effect of oral crude purslane extract administration on blood insulin level (IU/dl) in normal and streptozotocin induced diabetic male albino rats

\section{DISCUSSION}

Purslane is nutritious plant representing not only a major source of nutrient but also contain many protective factors. In many countries as in Turkey, purslane is considered as one of the medicinal herb used by diabetics ${ }^{(27)}$.

The results of the present work showed that the administration of crude purslane extract orally to normal and streptozotocin induced diabetic rats caused. hypolipidemia with reduction in the total cholesterol, triglyceride, low density lipoprotein and significant increase in high density lipoprotein.

The hypolipidemic effect of purslane may be attributed to melatonin content of crude extract ${ }^{(6)}$. The effect of melatonin on lipid profile could be attributed to its direct scavenger of free radical ${ }^{(28)}$. Also it could be due to indirect stimulation of the expression and activity of antioxidant enzymes ${ }^{(29)}$. It was reported that melatonin cause significant reduction in cholesterol, triglyceride, low density lipoprotein and significant increase in high density lipoprotein with decrease in atherogenic index ${ }^{(30)}$. Moreover, melatonin improved the diabetes mellitus and its related complication, such as impaired lipid profile ${ }^{(31)}$. Moreover, purslane extract caused significant decrease in blood glucose without change in insulin level in streptozotocin induced diabetic rats, which may be due to its melatonin content that improved the insulin resistance ${ }^{(32)}$. In addition, melatonin had antioxidative effect on insulin receptors, and also counteract tumor necrosis alpha that associated with insulin resistance ${ }^{(33)}$.

Coenzyme $10\left(\mathrm{Q}_{10}\right)$ has a hypolipidemic effect on normal and diabetic rats. This may be due to its action as electron carrier in oxidative phosphorylation and stabilizing the 
cell membrane with a potent scavenger of free radical ${ }^{(34)}$, It is also used hypercholesterolemia ${ }^{(35)}$.Moreover, the alpha tocopherol content of purslane may have a role in the hypolipedemic and hypoglycemic effects of purslane. This effect occurs through a chain breaking antioxidant that prevent propagation of free radical activities ${ }^{(\mathbf{1 3})}$. Also alpha tocopherol may causes hypolipidemia through stimulation of lipoprotein lipase, that clears chylomicrons from the circulation $^{(36)}$. In addition to $\beta$ carotene content of purslane increases the fecal excretion of cholesterol and normalizes the lipid metabolism ${ }^{(37)}$.

In addition, vitamin $\mathrm{C}$ content of purslane causes reduction in total cholesterol and improved the amount of low density lipoprotein, and also increased the action of insulin, due to non oxidative glucose metabolism ${ }^{(38)}$.

The hypolipidemic effect of purslane may be explained by selenium content of purslane which has an important role in formation and function of selenium dependent glutathione peroxidase, which prevent the accumulation of the oxidized low density lipoprotein ${ }^{(\mathbf{1 6})}$. Also zinc, manganese and copper form a part of the production of antioxidant enzymes $^{(17)}$. The hypolipidemic effect of crude purslane extract, may be attributed to its content of polyunsaturated fatty acids, omega $3^{(39)}$. The mechanism by which omega 3 caused hypolipidemia may be due to reduction of hepatic secretion of very low density lipoprotein ${ }^{(\mathbf{4 0})}$, or stimulation of fatty acid oxidation in the liver and skeletal muscles ${ }^{(41)}$, and so caused shift of triglyceride from storage to oxidation. Moreover omega 3 caused activation of lipoprotein lipase that catalizes the break down of triglyceride to fatty acids and glycerol $^{(42)}$. In addition omega 3 has antioxidant effect by decreasing oxidative stress $^{(43)}$.

The results of the present work showed significant reduction of blood glucose level in diabetic rats which were treated by purslane extract, which can be explained by the presence of omega 3 that are preventing the depletion of glucose transporter 4 in the muscle and adipose tissue ${ }^{(44)}$, and are improving insulin sensitivity and decreasing insulin resistance ${ }^{(45)}$. Moreover, omega 3 promote the glucose uptake and oxidation ${ }^{(46)}$.

Conclusion:

It is concluded that, the administration of crude purslane extract has beneficial effects on lipid and carbohydrates parameters both in normal and diabetic conditions. It is recommend to consume greater amounts of this plant regularly.

\section{REFERENCES}

1. Dweck A (2001): Purslane (Portulaca oleracea)- the global Panacea. Personal Care Magazine.; 2(4) : 7-15.

2. Connolly JD (2004): Medicinal Plants of the World. Phytochem; 65(5): 618

3. Zeghichi S Simo., Kallithraka S. and poulos AP (2003): The nutritional composition of selected wild plants in the diet of Crete. In: Simopoulos AP. and Gopalan C. (eds). Plants in Human Health and Nutrition 
Policy. World Rev Nutr Diet. Karger, Basel; 91: 22-40.

4. Obied WA., Mohamoud EN. and Mohamed O.S.A (2003): Portulaca oleracea (purslane): nutritive composition and clinicopathological effects on Nubian goats. Small Ruminant Research; 48(1): 31-36.

5. Rory PH., Mc Burney C., Griffinb C. and Alison AP (2004): The nutritional composition of African wild food plants: from composition to utilization. Journal of Food Composition and Analysis; 17(34): 277-289.

6. Simopoulos AP. (2001): Evolutionary aspects of diet, essential fatty acids and cardiovascular disease, Euro. H. J.; 3: 8- 21 .

7. Malek F. and Boskabady MH (2004): Bronchodilator effect of Portulaca oleracea in airways of asthmatic patients. J. of Ethnopharmacol.; 93 (1): 57-62.

8. Karimi G., Hosseinzadeh $\mathbf{H}$. and Ettehad N (2004): Evaluation of the gastric antiulcerogenic effects of Portulaca oleracea L. extracts in mice. Phytother. Res.; 18(6): 4847.

9. Leva E. and Dolev E (2002): Use of Natural Substances in the Treatment of Renal Stones and Other 172-179Urinary Disorders in the Medieval Levant. Origins of Nephrology; 22 (2-3): 172179.

10. Noumi E. and Yomi A (2001): Medicinal plants used for intestinal diseases in Mbalmayo Region, Central Province, Cameroon. Fitoterapia; 72(3): 246-254.
11. Eskander EF. and Won HJ (1995): Hypoglycemic and hyperinsulinemic effects of some Egyptian herbs used for the treatment of diabetes mellitus (type II) in rats. Egyp. J. of Pharm. Scien.; 36 (1-6): 331342.

12. Mousa HM, Omer $\mathrm{OH}$ and Ali BH (2006): Antioxidant levels in tissues of young and adult camels (Camelus dromedarius).J Physiol Biochem ;62(3):213-8

13. Rosenau $\mathbf{T}$, Kloser $\mathbf{E}$ and Gille L (2007): Vitamin E chemistry. Studies into initial oxidation intermediates of alphatocopherol: disproving the involvement of 5a-C-centered "chromanol method" radicals Org Chem ;72(9):3268-81.

14. Sarraga C, Carreras I, Garcia Regueiro JA and Guerrero $L$ (2006): Effects of alphatocopheryl acetate and betacarotene dietary supplementation on the antioxidant enzymes . Br Poult Sci ;47(6): 700-7.

15. Eaton $S$ (2006): The biochemical basis of antioxidant therapy in critical illness. Proc Nutr Soc ;65(3):242-9 .

16. Huang $K$, Liu $H$, Chen $Z$ and Xu H (2002): Role of selenium in cytoprotection against cholesterol oxide-induced vascular damage in rats. diabetes. Clin Sci ; 98: 2130.

17. Vasil'ev AV, Ivakhnenko VI and Mal'tsev GIU (2006): Changes in kinetic properties of superoxide dismutase and glutathione peroxidase in the liver and erythrocytes from rats during deficiency of protein and additional dietary administration 
$\mathrm{Cu}, \mathrm{Zn}, \mathrm{Mn}$ and Se. Biomed Khim; 52(4):384-93.

18. Chan K., Islam MW., Kamil M., Radhakrishnan R. and Zakaria M.N.M (2000): The analgesic and anti inflammatory effects of portulaca oleracea L. Subsp. Sativa (Haw.) Celak. J. of Ethnopharmacology; 73: 445 -451 .

19. Gupta A., Brahmbhatt $S$ and Sharma AC (2004): Left ventricular mitogen activated protein kinase signaling following polymicrobial sepsis during streptozotocin-induced

hyperglycemia.

Biochim.

Biophys. Acta.; 1690: 42-53.

20. Chen H., Shi YP and Liu JY (2003): Determination of noradrenaline and dopamine in Chinese herbal extracts from Portulaca olearacea L. by highperformance liquid chromatography. J. Chromatogr. A.; 1003(1-2): 127-32.

21. Fossati $P$. and Prencipe $L$ (1982): Triglycerides determination after enzymatic hydrolysis. Clin Chem.; 28: 20772080.

22. Ratliff CR. and Hall F (1973): Laboratory manual of clinical biochemistry. Scott and White Memorial Hospital Publications office. Temple, Tx.

23. Richmond W (1973): Enzymatic determination of cholesterol. Clin. Chem., 19: 1350-1356.

24. Fruchart JC (1982): Separation of low density lipoproteins. Rev Fr Des. Laboratories; 103: 7-17.

25. Burrin D

(1994): Immunotechnical technique in principles and technique of practical biochemistry. Wilson K. and Walker J. eds, $4^{\text {th }}$ edition; ch. 2: $65-109$.

26. Tietz NW (1986): Determination of blood glucose, Text book of clinical chemistry WB Saunders. Co. London, Philadelphia, 796.

27. Lans CA (2006): Ethnomedicines used in Trinidad and Tobago for urinary problems and diabetes mellitus. J Ethnobiol Ethnomedicine ; 13 ;2-45.

28. Deriaz $O$, Couture $P$ and Bergeron J (2007): Sequence variants in the melatonin-related receptor gene (GPR50). Current Opinion in Clinical Nutrition \& Metabolic Care; 10(2):215-263

29. Nishida S (2005): Metabolic effects of melatonin on oxidative stress and diabetes mellitus. Endocrine; 27(2):131-6.

30. Hussein MR, Ahmed OG, Hassan AF and Ahmed MA (2007): Intake of melatonin is associated with amelioration of physiological changes, both metabolic and morphological pathologies associated with obesity: an animal model. Int $\mathrm{J}$ Exp Pathol ;88(1):19-29.

31. Klepac $\mathbf{N}$, Rudes $Z$ and Klepac R (2006): Effects of melatonin on plasma oxidative stress in rats with streptozotocin induced diabetes. Biomed Pharmacother; 60(1):32-5.

32. Kanter $M$, Uysal $H$ and Sagmanligil HO (2006): Depression of glucose levels and partial restoration of pancreatic beta-cell damage by melatonin in streptozotocin-induced diabetic rats. Arch Toxicol ;80(6):362-9.

33. Anwar MM and Meki AR (2003): Oxidative stress in streptozotocin-induced diabetic rats: effects of garlic oil and 
melatonin.Comp Biochem Physiol A Mol Integr Physiol; 135(4):539-47.

34. Rauscher FM, Sanders RA and Watkins JB (2001): Effects of coenzyme Q10 treatment on antioxidant pathways in normal and streptozotocin-induced diabetic rats. $\mathrm{J}$ Biochem $\mathrm{Mol}$ Toxicol. ;15(1):41-6.

35. Belaia OL, Kalmykova VI and Ivanova LA (2006): Experience in coenzyme Q10 application in complex therapy of coronary heart disease with dyslipidemia . Klin Med (Mosk) ;84(5):59-62.

36. Costa VA and Vianna LM (2005): Effect of alphatocopherol supplementation on blood pressure and lipid profile in streptozotocin-induced diabetes mellitus in spontaneously hypertensive rats Clin Chim Acta ;351(1-2):101-4.

37. Kaliora AC, Dedoussis GV and Schmidt H (2006): Dietary antioxidants in preventing atherogenesis. Atherosclerosis; 187(1):1-17.

38. Manjunatha S, Jaryal AK, Bijlani RL and Sachdeva U (2001): Effect of Chyawanprash and vitamin $\mathrm{C}$ on glucose tolerance and lipoprotein profile. Indian J Physiol Pharmacol; 45(1):71-9.

39. Srivastava $M$, Banerji $R$ and Rawat AK (2006): Fatty acid composition of some medicinally useful seeds. J Herb Pharmacother ; 6(1):41-7.

40. Park Y. and Harris W (2003): Omega-3 fatty acid supplementation accelerates chylomicron triglyceride clearance. Journal of Lipid Research; 44: 455-463.

41. Ntambi JM and Sampath $H$ (2005): polyunsaturated fatty acid regulation of genes of lipid metabolism. Annual Review of Nutrition; 25: 317-340 .

42. Ory DS (2007): Chylomicrons and lipoprotein lipase at the endothelial surface: bound and GAG-ged?. Cell Metab ;5(4):22931.

43. Suresh Y and Das UN (2004): Long-chain polyunsaturated fatty acids and chemically induced diabetes mellitus. Effect of omega-3 fatty acids. J. of Nutr.; 19(3): 213-28.

44. Delarue J., Le Foll C., Corporeau C. and Lucas D (2004): N-3 long chain polyunsaturated fatty acids: a nutritional tool to prevent insulin resistance associated to type 2 diabetes and obesity?. Nutr. Dev.; 44(3): 289-99.

45. Holness M., Smith N. and Germma K (2004): Acute[omega]-3 fatty acid enrichment selectively reverses high saturated fat feedinginduced hyper secretion but does not improve peripheral insulin resistance .Diabetes; 53: 166 171.

46. Aas V., Rokling - Andersen MH., Kase ET. and Thoresen GH (2006): Eicosapentaenoic acid (20:5 n-3) increases fatty acid and glucose uptake in cultured human skeletal muscle cells. J. Lipid Res.;47(2): 366-74. 


\title{
تأثير مستخلص نبات الرجلة على بعض أوجه الأيض الغذائي للاهون

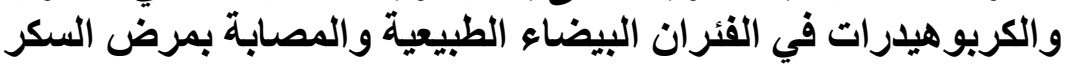

\author{
سلمى علوى نصار --رزق الخولى - رومبيساء على الثربينى

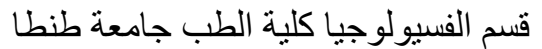

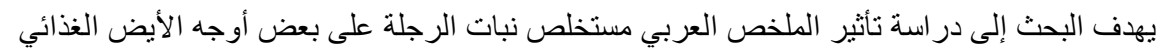

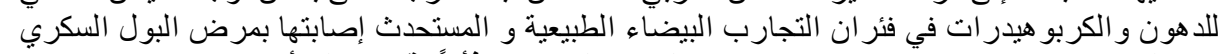

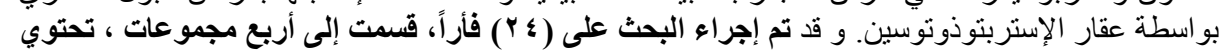 \\ كل منها على ستة فئرانً.

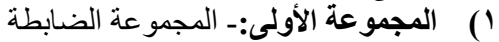

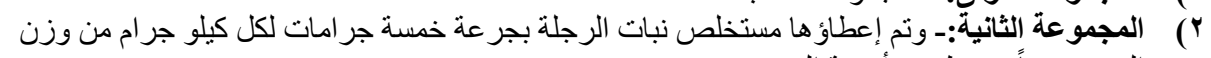 \\ الجسم يو مياً عن طريق النية: أنبو إعبة المعدة.

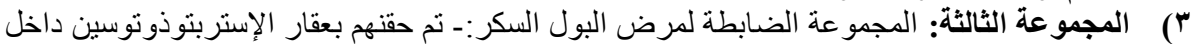

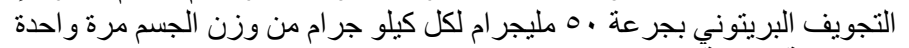

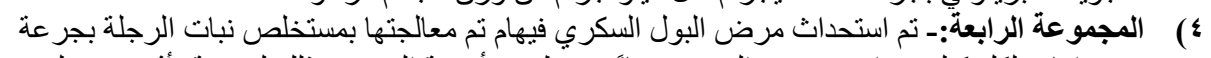

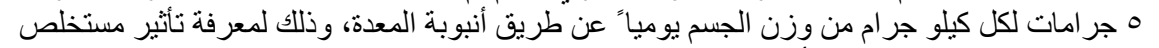

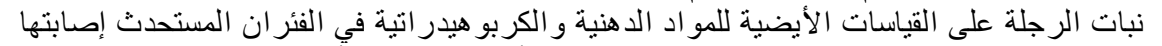

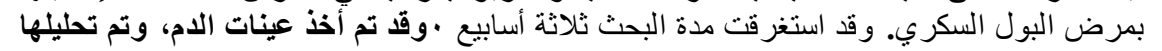

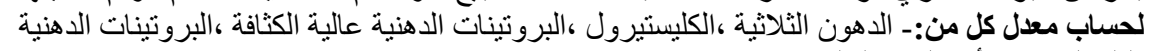

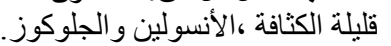

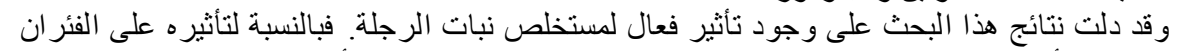

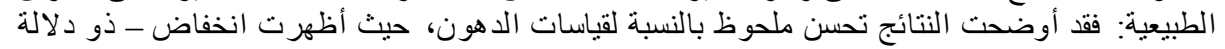

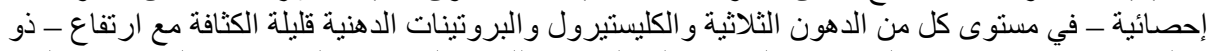

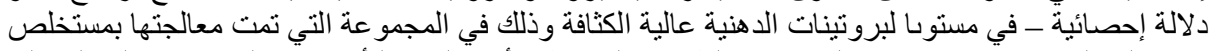

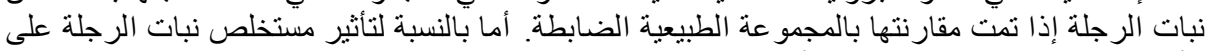

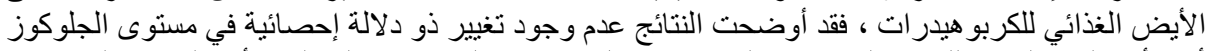

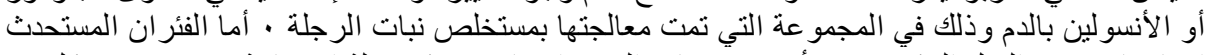

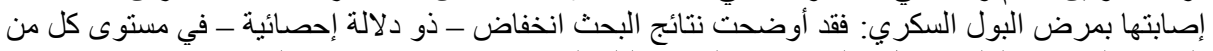

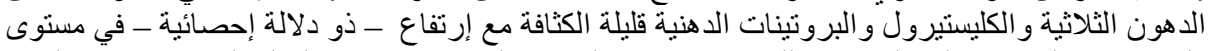

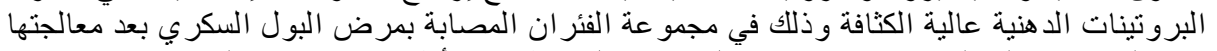

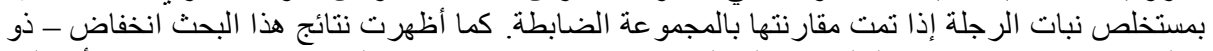

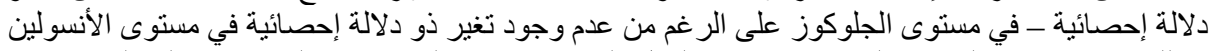

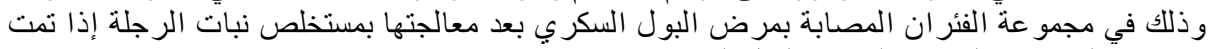

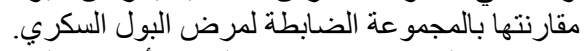

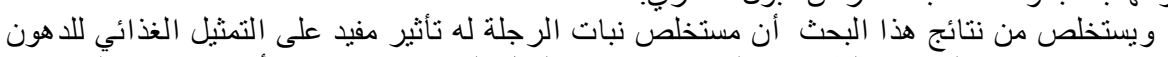

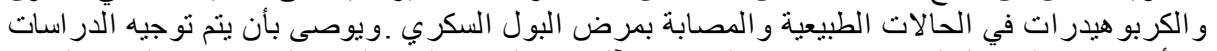

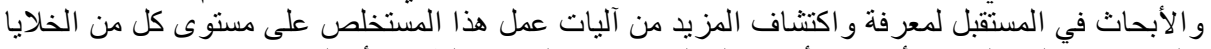

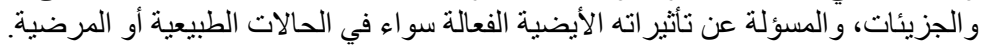

